\title{
Opinion
}

\section{Environmental education - an approach based on the concept of life}

\author{
J. FOURIE, S.C.J. JOUBERT and J.A. LOADER
}

Fourie, J., S.C.J. Joubert and J.A. Loader. 1990. Environmental education - an approach based on the concept of life. - Koedoe 33(1): 95-109. Pretoria. ISSN 0075-6458.

Environmental education is described as an enterprise aiming at a philosophy of life and therefore as a matter of life. This suggests the concept of life as a natural foundation for an approach to environmental education. Therefore a reflection on the phenomenon of life is offered in which the 'philosophy of life' or vitalist philosophy is reviewed. It is argued that life is a multi-levelled phenomenon and that a monolithic view of life is inadequate. A functional definition of life is proposed in which the microbiological description of life, its link with the abiotic aspect of reality, its other relationships and its spiritual potential are respected. This is used as the ground for an exemplary discussion of life at the levels suggested by the philosophical reflection, viz. life and the individual (which concentrates mainly on the biological aspect), life and the community (concentrating on the social aspect), life and the ecosystem (concentrating primarily on the relationship between abiotic and biotic), and life and the cosmos (which reaches the limit of the authors' task). The need for an ethic is related to these levels and the idea of responsibility is developed with recourse to ancient texts in which comparable ethical implications for the environment are contained. Finally, some practical suggestions are made for implementing the results of the argument in environmental education.

Key words: environmental education, life, philosophy of life, levels of life, ethic.

J. Fourie and S.C.J. Joubert, Kruger National Park, Private Bag X402, Skukuza, 1350 Republic of South Africa; J.A. Loader; Faculty of Theology, University of South Africa, P.O. Box 392, Pretoria, 0001 Republic of South Africa.

\section{Introduction}

Environmental education has become an important branch of what is often called the 'ecological movement', 'ecological awareness', 'environmental awareness' or 'environmental conservation'. Centres for the purpose have in recent years been springing up all over the world, not excluding South Africa, and much is being done by both 
such institutions and official educational programmes. The National Parks Board has also become part of this effort and is contributing in various ways, like film and slide shows, exhibitions, information services, competitions, the conducting of trails and bush camps as well as several other activities of the Communications Section of its Department of Research and Communications. Our purpose with this article is to contribute to the undertaking by reflecting on the foundations of environmental education and by offering some thoughts on the ramifications involved.

The first step of the argument to be developed here is an explanation of our view of environmental education and its aim.

Environmental education is the guidance of people

- to the insight that they belong to nature,

- to the experience of wonder and joy in nature, and

- to the acceptance of the responsibility to respect nature as the sustenance of life.

This article has been completed prior to the publication of the White Paper on Environmental Education by the Department of Environment Affairs (1989), but it is worth noting that much the same emphasis is placed there on aspects like recognition of the environment in its totality, interrelationships, interdependence, human responsibility and the permanence of the attitude called for. Although we have not been directly influenced by the Deep Ecology Movement in the development of our argument, our'use of the concept of life, of humanity as a part of nature, interdependence, responsibility and the necessity of concentrating on the roots of the matter rather than on the symptoms, does show similarity to the way these ideas function in the Deep Ecology Movement (cf., for a summary, Rothenberg 1987:185-190).

The aim of the whole enterprise is, on the one hand, to achieve a change of attitude and a resultant change in behaviour in as far as one or more of these aspects are lacking. On the other hand it is to strengthen the attitude and develop these aspects in as far as they are already present in individuals and groups, whether these are adults, young people or children. This means that environmental education aims at fostering a permanent attitude towards nature and therefore towards oneself. Another way of putting this is that environmental education aims at a philosophy of life. In this context the term 'life' becomes multi-dimensional and refers to a way of life (a philosophy of how one should conduct one's life) as well as to the phenomenon of life (a philosophy about what life is in essence).

If this is what environmental education is and what it aims at, then it is nothing less than a matter of life. Therefore it is logical that our approach be based on the same concept: the concept of life. However, this does not mean that we select the concept of life merely because we have stumbled onto the need for something to use as the foundation for our programme of environmental education. On the contrary, the need for environmental education derives from the importance of life - not the other way round.

Because life is a focal point (though not the only point of importance) in the environment (cf. Joubert 1986), therefore environmental education has to focus on life.

Furthermore, because environmental education aims at the development of a philosophy of life, the concept of life is therefore a sound organising principle for moulding an approach to such an undertaking.

In addition, the concept of life is suited to the purpose since it opens many relevant perspectives. The various meanings for which the word 'life' can be used, correspond 
to the various levels at which the phenomenon of life operates. As we shall show further on, these form the framework of our argument. Therefore the concept of life is also useful in addition to being intrinsically important for our purpose.

If the presupposition of the importance of life is accepted, the authors put forward the hypothesis that this concept enables us to work out an approach to environmental education which facilitates the acquisition of an embracing philosophy of life entailing sound values that can be applied in practice. Therefore reflection on the phenomenon of life is necessary. Thinking about life reveals the multi-levelledness of the phenomenon, which relates to the interdependence of its facets, and this again leads to the aim of environmental education, viz. the idea of responsibility.

\section{Reflection on the Phenomenon of Life}

The difficulty of defining what life is and the vast amount of thought that has gone into Western philosophy of life cannot be bypassed in an approach based on the concept of life. The first question is how we should define life.

Most people are quite at ease in distinguishing life from its opposite. This intuitive distinction pays no attention to what life is distinguished from. A dead animal, a dead tree, a stone or a doornail are all regarded as 'dead'. By the same token, abiotic phenomena like heat, air or water are not generally thought of as specifically 'dead' (on the contrary, these three phenomena are often even thought of as living!). However, when one begins to think about the opposite of life, the difficulty appears of defining what life is in terms of what it is not. Clearly life is not only the opposite of 'abiotic', since dead animals and plants would then have to be regarded as possessing life. Likewise, life cannot merely be defined as that which has not died, since abiotic phenomena have not died and would then have to be thought of as living.

Turning to more sophisticated ways of saying what life is, it would be possible to define life in purely physico-chemical terms. Life would be that property which exists where an organism is formed by a cellular construction, made possible by the production of proteins which in turn originate from the combination of amino acids according to the codes provided by the linear molecules of deoxyribonucleic acid (DNA) of the genes contained in the chromosomes of the cellular nucleus (usually). This is not so much a clarification of the origin of life as a microbiological description of life. A similar view of life is even supported by theologians like the scientist and philosopher Pierre Teilhard de Chardin (cf. Teilhard de Chardin 1966:24). However, the question now arises whether a microbiological/molecular description is adequate to cover all levels of life. Teilhard de Chardin has much to say in answer to this question, as we shall see below.

Many mechanistic explanations of life exist. A good example is the sweeping hypothesis recently put forward by James Lovelock, in which the mechanistic explanation of life is used to address also the question of origin. In this, the so-called Gaia Hypothesis, the whole earth is regarded as a huge responsive organism (Sagan \& Margulis 1984:66) in which life is not governed by physico-chemical events, but the opposite happens. That is, life is not called forth by something else, but itself calls forth its conducive environment in order to survive. In other words, life itself becomes the governing principle. Paradoxically, this is reminiscent of the vitalist philosophies of the nineteenth century whose proponents regarded life as the essence of reality while reacting vehemently against mechanistic thinking (see next page). 
Mechanistic theories may be attractive on the biological level, but they become inadequate if extended to cover all levels of life. If all aspects of all levels of life are governed by strictly pre-determined laws, then there could be no room for human creativity, no room for freedom and therefore no room for decisions and responsibility. A 'physically closed system' (Popper 1972:219) cannot account for all the aspects of life since it has to be deterministic and is therefore insufficient as a general principle. What we can say, is that physico-chemical processes and laws are necessary for life, but not that they are the only factors involved (cf. Du Toit 1988:8).

During the nineteenth century determinism dominated science. It deeply influenced not only the natural sciences, but also other branches of scholarship, theology and philosophy included. This was bound to evoke reaction, which indeed came in the form of the so-called philosophy of life, or vitalist philosophy.

Certain philosophers of life protested against the explanation of all that happens as mechanistic processes of cause and effect. According to them many aspects of life could not be explained in this way, and they replaced the idea of physico-chemical causes by that of ends, that is, by the principle of finality or 'directiveness', as it is called by the British thinker, E. S. Russell (Russell 1945). Not so much the question, 'What causes the events of life?' as 'Where is life heading?' became their interest. Moreover, their protest was also against rigid intellectualism according to which rational propositions could sufficiently explain life and its events. Since both of these basic traits of vitalist philosophy are very much in evidence among modern environmentalists (cf. Sterling 1985), it is obvious that the philosophers of life and their philosophies are important for our reflection on the concept of life in the context of environmental concern.

The German embryologist and subsequent philosopher, H. Driesch (1867-1941) initially used the mechanistic model to explain life, but gradually realised that this model must be inadequate, since machines cannot reproduce themselves or adapt to varying circumstances. Therefore he developed the notion that there must be an invisible power that holds the parts together. This power cannot be analysed by science, but it is necessary to explain how the totality of life is more than the sum of its constituent parts (Driesch 1922). Another form of this type of philosophy can be seen in the thinking of the Englishman, C.D. Broad (1887-1971). According to him it is not necessary to conclude to the presence of an invisible, external power. He concludes that as we can see how various life-forms develop out of previous (and existing) ones, the nature of a living organism is indeed determined by its chemical (and physical) components while at the same time being more than the sum of those components (Broad 1925). Analogous ideas have been developed by the British-American philosopher A.N. Whitehead 1861-1947), who thought of reality as a continuous process of development which also enabled him to regard humanity as part of nature and not as something working against it (Whitehead 1929).

Another theologian who was influenced by vitalist thinking is the German physcian, philosopher and musicologist, Albert Schweitzer (1875-1965). Since his motto, 'Reverence for Life', occurred to him intuitively in September 1915, it became world famous. However, the influence his writings and thoughts exerted globally, stems more from his practical philantropy practiced in central Africa than from his philosophical writings. If this is kept in mind, it is understandable and significant that he developed his ethic - 'to sustain life equals good and to damage life equals evil' - under the influence of his motto and not the other way round. 
One of the most important 'philosophers of life' was Henri Bergson (1859-1941). He incorporated the whole spectrum of life into his work - from the smallest organisms to the human being, which also included the human society. This holistic approach resulted in a natural interest in the spirit. According to Bergson, the essence of life, its direction and sense can only be apprehended by focussing on the spiritual aspect of life. If one is to understand life, it is to be approached not from its more elementary aspects (the task of, for instance, physico-chemical analysis), but from its higher aspects, those of the spirit, from which one can oversee the whole of the spectrum of life (Bergson 1919). This again points in the direction of the apparent impossibility of counterposing spirit and matter or humanity and nature.

It is interesting to note that the holism of the South African J.C. Smuts (1870-1950) and other thinkers of the 'holistic school' are sometimes related to the philosophy of life. According to the holists, who pay much attention to biological studies, the phenomenon of life contains a 'totality' to which everything is to be related. This means that they too do not work with an external power in the way Driesch does, but with a vital power within life itself.

Various thinkers came to develop views in which the inner, spiritual, aspect of life was emphasised in much the same way as in the philosophy of Bergson. It became more and more obvious that 'life' could not be restricted to the biological realm only. Wilhelm Dilthey (1833-1911) related the inner experience of human life ('Einfühlung') to the flow of history, while the inner experience of life also stood at the centre of the philosophy of life expounded by Georg Simmel (1858-1918). This was also done by the Spanish thinker, J. Ortega y Gasset (1883-1955) who distinguished vitalism that focusses on organic life as such, from vitalism that centres on experienced life or 'lived life'. This trend was partly indebted to the philosophy of life as developed by Friedrich Nietzsche (1844-1900), not because of his interest in the relationship between the biological and other aspects of life, but because of his fundamental view that reality is life and Nietzsche's cultural criticism which emanated from this point of view.

One of the most brilliant of the vitalist thinkers was the French theologian Pierre Teilhard de Chardin (1881-1955). His versatility in the fields of geology, paleontology, philosophy and theology made him one of the most noteworthy thinkers of modern times. The main contours of his thought resemble those of Bergson in that he refuses to separate the life of the spirit from the life of organisms. He postulates the evolution of one primeval matter through the different stages of life. The primeval matter evolves into the life of organisms like plants and animals ('vitalisation'), then develops further into human life ('hominisation'), and also into social structures ('socialisation'). Teilhard de Chardin does not stop here, but draws the line of evolving life still further - to God ('divinisation'). This happens through death, and Teilhard de Chardin accordingly interprets the central Christian symbol of the death of Christ as the transformation of the human into the divine. In this way he makes it possible for science to proceed to religion without adapting science to religious prejudice along the way or committing science to religious doctrines.

There are many currents within the general philosophical direction called the 'philosophy of life' or 'vitalism'. We need not accept all that the vitalists held to appreciate the validity of the main contribution the movement made to Western philosophy and its importance for our present concern. This is the insight that life is more than physics and chemistry. However important life as a phenomenon at this level may be, there are other aspects of life that need to be taken seriously as well, both 'inward' and 'outward'. That is, life also comprises the spirit with its activities of feeling and thought, 
and it reaches out beyond the individual into societies and interrelationships. That is why the same phenomenon that exists at the level of unicellular organisms also exists at more complex levels where spirit, thought and feeling operate - at those levels where responsibility is called for. As if the complexity of life at the physico-chemical level is not deep enough - it is further intensified beyond comprehension by the insight that life extends further in ever widening ripples. The mystery of how the lifeless becomes the living at molecular level has its counterpart on the vast level of ecosystems where specific forms of life can only come forth from specific forms of abiotic existence. Specific lifeless geological formations cause specific soils with specific minerals which specific plants convert into specific life forms, which in turn sustain other life forms. And without these, human life is possible at neither the individual nor the community levels. Finally, there would be no activity of the spirit, no creativity. As knowledge grows, the interrelationships between all the levels and aspects of life and even between lifeless and living are not becoming easier to grasp, but more mystifying, more wonderful.

From the above it should be clear that we shall have to design our life-based approach to environmental education so that it incorporates at least the three levels that have been presenting themselves repeatedly in our exposition so far, viz. the individual, the society (or population), and the ecosystem. Although it would be possible to develop an approach limited to these levels, such a design would leave a serious aspect unaddressed, notably the perspective opened explicitly by Teilhard de Chardin and implicitly by the scientists and philosophers who have shown us the mystifying side of life and reality. Wondering at life, loving it, and the very living of it as part of nature demand attention to an essential aspect of human experience of life and nature. Therefore we shall also include a fourth level, that of God.

\section{The levels of life}

Having reviewed some of the main aspects of the philosophy of life, it remains for us to say what life is. It should be clear that we cannot content ourselves with a monolithic definition that would only be adequate to account for one level of life. Neither could we rely on the intuitive clarity most people have about what is 'alive' and what is not. It is true that living organisms require nutrition, oxidation and shelter, that they are born, grow, decay and die. But if life is found on several levels and is characterised by processes rather than static situations, then our definition of life should reflect these. We therefore offer a functional definition of life designed for our purpose, with full cognizance of the fact that other definitions are possible for other purposes.

Life is a teleological process of increasingly complex relationships rooted in the abiotic aspect of reality, developing through the stadia of spontaneous and dynamic regeneration by species and culminating in consciousness.

The following statements can be accommodated by this definition:

1. Life is a process rather than a state.

2. The life process is headed in a direction (teleological directiveness).

3. There are abiotic physico-chemical elements at the base lines of life.

4. Life is part of a continuum involving the emergence of the biotic aspect of reality and further development.

5. On all levels life consists of interrelationships. 
6. The species participating in life regenerate themselves spontaneously.

7. At least in the higher forms of life consciousness is found, which may entail spiritual activity.

At the one end of the spectrum such a definition leaves full scope for science to investigate the underlying question of the origin of life and to give molecular and/or microbiological descriptions of life; being open-ended, it leaves room at the other end of the spectrum for the mind and the spiritual aspect of life; and, emphasising as it does the ideas of processes and interrelationships, in between it contains the space needed for ecosystems and the related facets of interdependence.

Let us now take a closer look at life on the four levels that have been prepared by our reflection, notably life and the individual (which will concentrate mainly on the biological aspect), life and the community (which will concentrate on the social aspect), life and the ecosystem (which will concentrate primarily on the relationship between abiotic and biotic), and finally life and the cosmos (which will bring us to the limits of the task we have set ourselves).

\section{Life and the individual}

Consider the simple statements, 'He is still alive', referring to, say, a human being, and, 'Some predators swallow their prey live'. In popular parlance this would mean that an individual is in a condition in which the metabolism and processes that cease at death are still in operation. The concept of life, when used in this way, is usually thought of in biological terms. Although life at this level is an extremely comlex phenomenon, its commonly experienced outward manifestations present this level as the obvious one to begin with.

A living organism consists of a great number and variety of different components. Take the human body as example: it consists of skin, bones, muscles, hair, nails, blood, nerves, diverse kinds of tissues and so on. These elements combine to form systems in the body, like the circulatory system, nervous system, digestive system, respiratory system, and the like. The systems, again, interact with one another and with certain organs by means of many processes, like transmission of oxygen from the air to the blood. Although the systems have different functions, they function in harmony with one another for the well-being of the individual. They convey the essential sustenance (minerals, oxygen, water) to the various areas where they are needed, but they also convey the waste products to where they are disposed of. Therefore these processes are of a cyclic nature.

Cyclic processes are of a repetitive nature like the continuous cycle of day and night or summer and winter. However, this does not mean that they merely go round and round in a never-ending circle. The successive cycles are separated in time and therefore attain a spiralling character. The time dimension sees to it that these processes have directiveness, to use Russel's term quoted above. The life processes in the individual are going somewhere and taking the individual with them. If any of these processes are interrupted or if the harmonious functioning of the systems is impaired, the individual will suffer a loss of the quality of life and may even not be able to survive.

The individual strives to maintain stability and resists any changes of condition that may endanger that stability. If, for instance, a person has an infection, the processes in the body will resist the change that has taken place and endeavour to rid the body 
of the micro-organism that has caused the infection so that the body can return to its former healthy state. In this way stability is strived after. The striving for stability is evidenced above all by the will to survive, the strongest force in the individual.

The ways in which an individual is capable of performing life-supporting activities are analogous to the biological processes which seek to maintain an optimum quality of life in the individual's body. Looking for food, providing shelter, avoiding danger, communicating and the like are processes by which an individual seeks to protect the quality of life. Running into danger and losing a leg as a result does not necessarily lead to death, but it upsets the stability of a life in which all the abilities characteristic of the human species are no longer present. Therefore individuals design life-processes to fulfill basically the same functions as the stability-seeking processes of the body systems.

Influences outside the individual also affect life and the processes within the individual. These influences are also cyclic, like the 24 hour day-night cycle. The individual needs sleep and adapts to the cycle of light and darkness in order to satisfy this need and maintain the normal functioning of life-processes. Even while asleep, the processes in the body continue so that stability is maintained.

However, these processes cannot maintain stability indefinitely. One of the most prominent characteristics of life at this level is its unstable equilibrium. Not only do diseases impair the life-processes from time to time, but the spiralling effect of time causes the processes to become weaker when the individual becomes old. In the end the processes cannot maintain the life of that individual any longer, and death sets in. Death is part of life. The life process does not end at death. A body becomes part of the soil again. A carcass decays and replenishes the minerals of the soil from which new life is to spring. The cyclical aspect of life and death was already taken seriously millennia ago, as we know from ancient myths that reflect on life and death: dust to dust and a return to the earth from which life was taken (Genesis 3:19).

There is a second way in which the individual ensures that death is not the end of life, viz. procreation. Individuals reproduce themselves in order to maintain the life of the species. This links with death in a twofold way: as the spiralling effect of time in the life cycle of the individual causes deterioration, the new generation brings vitality to the species, which means that decay in the one individual is offset by growth in the other. Secondly, the death of individuals is necessary to make room for the life of other individuals, because the carrying capacity of their environment cannot support an indefinite number of individuals. Had there been no death, there could have been no procreation. Had there been no procreation, life and its processes would not have been what we know and experience as life. Therefore death is a necessary part of and sustenance for life. Here the interrelationship of the life of the individual and that of the community becomes apparent. The one brings forth the other and lives on in the other. Therefore it is the same phenomenon that exists on various levels.

\section{Life and the population}

In a population processes are manifested in the form of social behaviour patterns. These patterns are also processes and are analogous to the biological processes which sustain the body of a living individual. Consider the following common expressions: 'family life in ancient Israel'; 'university life in Johannesburg'. Here the term 'life' means social relations in which the members of specific communities participate. In 
the first case the processes governing the relationships of the basic social unit in an ancient nation are seen as 'life'. In the second those processes and relationships obtaining in a specific social stratum of a specific modern city are seen as the 'life' of that stratum.

When we speak of the social life of a troop of baboons, the same happens: we refer to the processes and relationships governing a society of baboons. In an animal population, or society, we find behaviour patterns (processes) like leadership, submission, territorialism, control, courtship behaviour, reproductive behaviour, protective behaviour (like a mother hiding its baby), mother-child relationships, communication forms (auditive, visual, chemical and attitudinal communication). These forms of behaviour are "aimed" at bringing about organisation within the population for the purpose of the survival of the population and achieving maximum benefit for the population.

The activities within the population are coordinated to serve a common objective: survival of the specific form of life of the population. Here 'life' means means 'way of life'. It is not identical with biological life, but serves that life. So we see again how life at the one level is intimately interwoven with life at the other level. The process of socialisation is analogous to the inflow of sustenance because it is of a life-giving nature. For instance: new members of an insectivorous society must get to know certain vital signs like the fact that brightly coloured grasshoppers are a threat to life (they may be poisonous when consumed) and a lion cub has to be taught by its mother how to hunt in order to survive. Therefore elements of communication are needed for achieving social coordination so that life can be sustained. The life of the individual and the life of the population are reciprocally related. Another example: just as the removal of waste or redundancy is necessary for the maintenance of life at the individual level, it is also necessary at the social level. We have already touched on this phenomenon above (on the necessity of death for life), but it can also be observed in social behaviour patterns. Redundant impala males, for example, are removed by social processes such as competition in addition to external factors such as parasitism and predation.

Competition is a powerful process, especially when the numbers of a population reach a high density. It assists in the elimination of the weaker element, thereby interacting with and facilitating the processes of natural selection and population dynamics. It assists external processes like parasitism in that the weaker element is made more vulnerable to diseases, and internal processes like establishing a hierarchy within the population which creates social orderliness.

Like life at the individual level, life at the population level shows resistance to change that endangers its survival. As the example of competition has illustrated, population numbers are an important factor in the life of the community. This is further exemplified by an increased rate of breeding when the population decreases, and a decreased rate of breeding when the population increases to a high density. Like life at the individual level, life at the population level too shows a will to survive. This is evidenced by the selection of the strongest males for breeding purposes so that the progeny may be best adapted for the given environment. All social behaviour, then, is necessary, since it contributes towards the survival, maintenance and perpetuation of the population. Therefore the existence of such a population is life, since 'life is a process of relationships developing through stadia of spontaneous and dynamic regeneration'. 
It is interesting to note that sociologists describe human societies in much the same way as our description of life. For example, a society is described as a system of interrelated parts and repetitive patterns of activities, tending toward a state of equilibrium, and receiving a contribution toward the latter from all the forms of patterned action (cf. De Fleur \& Ball-Rokeach 1982: 16). In passing, we may also note the interesting fact that the father of positivistic science, Auguste Comte (1798-1857), assigned sociology to the natural sciences as 'social physics', and not to the humanities.

\section{Life and the ecosystem}

Our definition of life states that it is rooted in the abiotic aspect of reality. This can be observed in the life of the individual, which is characterised by complex physico-chemical elements and processes, but not only by these. We have said earlier that the mystery of the lifeless that becomes the living at molecular level (cf. Teilhard de Chardin) has its counterpart on the level of the ecosystem. The parallel is strikingly thorough.

Consider the following common expressions where the term 'life' occurs: 'life forms of the Malelane mountain region'; 'life forms of the basaltic savannah land'. Biotic existence is clearly meant in both cases, but relationships between these forms of life and the abiotic aspects of geological substrata, soil type, altitude, undulating versus flat ground and the associated factors of northern and southern slopes, sunlight exposure, and the like are also implied. Common parlance thus supposes that life exists at the level of ecosystems. And rightly so.

Certain animal species can only live in particular localities because the plant life which sustains them is only found in those areas as a consequence of the fact that the soil type, water and other abiotic factors combine in a specific pattern in that area. The rootedness of life in the lifeless is nowhere so obvious as in the contemplation of landscapes and their associated animal life. One can observe here the same wonder that microbiologists marvel at when observing reality at molecular level. Again we see that life is not a state, but a process consisting of interrelationships. We have to do with relationships not only within the communities of species, but between species and between species and abiotic factors. These again form systems, this time on yet another level.

Some of the processes that are evident in the ecosystem are, for instance, soil formation, erosion, interspecific competition, niche separation, predation, decomposition, mineral recycling and natural selection.

The ecosystem is also capable of dynamic regeneration of its own form by means of processes like plant migration that colonise suitable areas with similar plant communities. By virtue of its diversity of component life forms it resists change that endangers its survival because it can oppose an equal variety of changing forces, thereby maintaining stability. Moreover, typical life functions can be seen in mineral cycles, food webs and energy flow, all of which operate within the ecosystem. And, similar to what happens in life at the individual and population levels, waste products are removed by several processes like decomposition, erosion, competition, predation, parasitism, species loss and others. All the elements and processes contribute to the life and survival of the ecosystem.

\section{Life and the cosmos}

Consider the following expressions: 'the spiritual life of the Middle Ages'; 'a lively 
performance of Haydn's oratorio The Creation'; 'colour comes to life in Van Gogh's art'. Popular parlance correctly implies that consciousness, spiritual activity, thought and creativity are aspects of life.

If consciousness, knowledge, reason, feeling and creativity are not aspects of life, then what are they? We shall leave aside the relevant question whether the anger, joy or pining in animals should be bracketed with the consciousness of the human mind not because it is unimportant as such, but because it is not necessary for our present purpose. In spite of its being immensely important, we shall not extensively develop the theme of life at the spiritual level, since it would exceed the task we have set ourselves in this article by far. It would suffice to remind ourselves of the vitalists and of the philosophies of Bergson and Teilhard de Chardin.

Feeling for nature, love of one's environment, joy in experiencing the wilderness, commitment to its survival - these are all activities of the mind, spiritual in nature. What we should face, is the fact that we cannot bypass the spirit if we are to develop an ethic towards the environment, that is, if we want to conserve the environment at all. Conservation is an ethical act (cf. Skolimowski 1984:45), and as such is rooted in the spirit. Is it, too, not a process designed to serve survival of life at all its levels, to serve their maximum benefit, perpetuation and stability? If so, then it is part of the teleological life process - working as it does towards an end. And is not this what environmental education is about? If environmental education aims at cultivating correct attitudes, it aims at mental attitudes, at ethical beliefs, at spiritual activity. And, since these concern conservation as participation in the process of life, environmental education is part of the life it serves. So, environmental education, as a branch of conservation, is a way of life. What we have done by using conservation as our example of spiritual life (instead of, say, religion or art), is to provide immediate evidence for the central theme of our argument, viz. that life is a continuum of processes on various demonstrable levels.

\section{An Ethical Code}

The inner logic of our argument has brought us to the consideration of an ethical code. Apart from what we have just said about conservation as an ethical act and about a way of life, consider the following statements: 'one should live correctly'; 'his life is an example to others'; 'his life is a mess'. Popular parlance uses 'life' and the verb 'live' to refer to behaviour, conduct, way of life.

An ethical code means that certain values are made normative for behaviour. These norms mould a conscience. So, a mental decision is asked of a competent individual. Competence to decide to accept a set of norms as the regulatory apparatus for one's conscience implies freedom of choice and responsibility. This motif is prominently present in ancient mythical texts bearing on the emergence of life, on nature and the relationship of humans to their environment (cf. Loader 1987:16-21).

In the biblical Creation Narrative of Genesis 1, the creation of abiotic and biotic creatures are narrated with utter symmetry of form and content and the creation process culminates in the emergence of man. Man is created in the image of God 'in order to' have dominion over their environment. These words give the purpose of creation in God's image. So man is created in God's image in order to have dominion. The image of God in man would then mean that he resembles God and rules like him. However, the Israelite king was not an absolute monarch, but subject to God, as we know from the Law of Kings (Deuteronomy 17:14-20). The king is supposed to foster 
and care for his subjects. This is the kind of king referred to in the Creation Narrative. Humans are to rule like God, following his model, which is loving and caring and as harmonious as the symmetry of the Genesis Narrative and the systems of life that we have been considering.

Another passage is the creation hymn found in Psalm 8. Here we find a poem just as carefully composed as the prose narrative of Genesis. The first half of the hymn proclaims the insignificance of man in creation. Man's almost nothingness becomes apparent when he is seen in the context of the vastness of his total environment. Yet, a sudden twist then comes. The second half of the poem proclaims the royal dominion of man. He is a king whose subjects are listed in a poetic index of species. These two aspects together, royal power and humility in the context of the environment relativise one another. The same is suggested by Joseph Haydn at the end of his magnificent oratorio, The Creation, where he reflects on the frailty of man called 'King of Nature'. This king is a vassal king, a king subject to the rule of an overlord. So the rule of man in nature again means ruling subject to the will of God - responsibility.

This is what we would advocate as the content of an ethical code in environmental education. Irrespective of their religious content, these texts are ancient reflections on the emergence of life, on man's place within nature as part of it, on his minuteness and simultaneously on his greatness which is the same as his responsibility for his environment. We think that our reflection on the phenomenon of life and its levels lead naturally to the same conclusion:

Thinking about the phenomenon of life leads to insight in the multi-levelledness of life, which in turn obviates its interdependent processes, which, again, necessarily leads to the category of responsibility.

Support for the call for a new ethical code has in recent years been forthcoming from many quarters. Much of what is often called the 'Deep Ecology Movement' is geared towards this end. The concepts used in this current of thought are sometimes strikingly similar to those developed in our argument, for instance the centrality of the concept of life, emphasis on starting from basics, on interrelationships, on humanity as part of nature, on spiritual activity in this context and on responsibility (cf. Rothenberg 1987:185-190). Especially the insight that spiritual values play a part in science is being developed (e.g. Milbrath 1984; Skolimowski 1984; Sterling 1985), and, as Sterling points out, this is also supported from the side of physicists like Werner Heisenberg (cf. Heisenberg 1958:29) who also undermines the idea of valueless scientific investigation of nature. It is the foundation for Sterling's idea of 'Organic Systems' in the context of which not only the integration of human societies and natural systems become apparent, but ethical dimensions are also seen to be necessary for our thinking (Sterling 1985:197-206).

Actually the 'new' ethic is not so new at all, since it can be informed by the ethic of 'primitive' or 'primal' communities, where the 'new' insights have been held and practiced for centuries. Devall \& Sessions (1985) show that peoples like the Eskimo and the Indians had an 'intuition of deep ecology'. The surroundings in which they live 'are aware' and 'feel'; therefore they must be respected (Devall \& Sessions op. cit.). Indians respected life in all its forms, including that of the animals whose life was needed to sustain the life of humans, because they knew that they were 'one small part of the life on this earth' (Player 1979:22-23). Accordingly, there is much to be learned from 'primal cultures', that is, those cultures that can form a link between the 'sophisticated' cultures in which humans have learnt to overlook and forget their integration into the web of life. 


\section{Presentation}

Much can be said about an effective manner in which environmental education based on the concept of life can be presented in a practical way. This is, in fact, a topic in its own right. We shall only make some suggestions that are related to the concept of life.

The first concerns the salutary effect of being in the wilderness (cf. Suttie 1984). This is so commonplace a motif that it is in danger of suffering from the devaluation of anything that is given too much currency. However, clichés can be true. It certainly has been shown that physical presence in a wilderness context brings people into a more ready state to explore their own thoughts and feelings. Therefore environmental education can be enhanced by such a setting. On the other hand, we have argued that nature is not only 'out there', in the wilderness, as opposed to 'here' in the city where culture and civilisation are found. If one allows the wilderness setting of environmental education to become so overriding as to cultivate the harmful misconception of where 'real' life and 'real' nature is, then one of the basic tenets of environmental education (as we have defined it at the beginning of this article) is undermined, viz. the total integration of all life-processes and life-systems. Having said this, however, we nevertheless recognise the favourable effects of the wilderness for a 'transformative experience' (Brown 1987:2) and to 'align goal oriented behavior with essential values' (Brown 1987:5). Therefore bush camps are ideal settings for the purposes of environmental education, though not the only legitimate ones. Such camps are especially suited to guide people 'to the experience of wonder and joy in nature' (as we have also stated in the description of our view of environmental education).

In conclusion, we may take a look at some specific themes and techniques in a programme of such an effort. We suggest four main themes:

\section{Familiarisation}

This means getting to know the bush environment (soils, plants, animal spoor, droppings, etc.), and understanding the basics of an ecosystem (e.g. the trophic pyramid, energy flow, etc.) The aim is to cultivate the recognition of order in the system around the participants.

\section{Introduction to the concept of life}

The concept is introduced, the levels are attended to and illustrated as richly as possible by examples from the environment. In our experience a termite mound lends itself excellently to an explanation of life at various levels.

\section{The current state of the earth measured against the ethical code}

This main theme exposes the lack of ethical codes and ethically justifiable behaviour patterns. This could be done with reference to all the levels of life. Under this main theme a specific theme could be chosen, such as the sale of DDT to Third World countries (cf. Thomson 1986:163-166). This would, for instance, expose the imbalance of respect for the self and its needs over and against disrespect for all other instances and levels of life. This should be complemented by the positive counter-pole, viz. a search for alternatives which do comply with the ethical code. The participants should search for, discover and test these for themselves and be led to the insight that there often are several options, while the final choice is often determined by the individual's basic values. Participants should be led towards realisation of the practical implications of the ethical code. In the end they should realise that respectful existence with and in nature demands a radical departure from the idea that civilisation fights against nature in order to 'tame' it, since opposing nature is self-contradictory, being as it is opposition to that of which one is part. 


\section{The current status of conservation}

This theme is essential for it introduces the participants to what is already being done in the field of conservation, what its strengths and weaknesses are, and where each participant can fit in with a meaningful contribution.

For these purposes a programme which could be followed daily may look somewhat as follows:

06:00 Manifesting the theme for the day in the veld. On the first day this may be an introduction to the bush environment, or examples of trophic pyramids, followed on the second day by the levels of life as illustrated in a termite mound, while on the third day the current state of the earth measured against an ethical code could be attended to.

12:00 Lunch, followed by a period of reflection by the participants. Then a specific assignment may be given them, which can be discussed in smaller groups and then by the group as a whole.

16:00 Creative expression of the individual participants around sunset.

As for specific techniques to apply in such a programme, the following is suggested:

1. After an hour or so of walking in the morning, the participants can be taken to a pleasant spot and sit by themselves, out of contact with one another, to 'tune in to the bush', i. e. to experience life in the wilderness, which includes being alive in the wilderness oneself.

2. Allow the same solitude in the afternoon as well. Some creative thoughts and discoveries of one's own potential can emanate from these moments. If spontaneous discussion groups form themselves, these should be allowed to develop, since they usually enhance creativity and the testing and internalisation of ideas.

3. At night, around the camp fire, the participants should be allowed to share their views, experiences and questions. It should, however, always be spontaneous and never forced.

4. On the last afternoon the participants may make their resolutions about their ethically substantiated actions as living human beings in and for their particular environment to which they intend returning.

\section{Conclusion}

We do not claim that the approach developed in this article is the only one possible. But we do think that it has advantages in that it is holistic in proceeding from the phenomenon of life. It is not coincidental that the philosophy of holism is closely associated with the philosophy of life, as we have seen in our reflection on the phenomenon of life. The advantage is that the phenomenon of life allows for inclusion of all the aspects relevant to environmental awareness. From the abiotic to the biotic, from experience of joy and wonder to the acceptance of responsibility - these are all included and open wide perspectives for self-realisation, not only in 'the field of conservation', but in life itself. Then the triad of knowledge, inner experience and responsibility spirals forward in a life that is lived and that contributes to life. 


\section{References}

BERGSON, H. 1919. L'énergie spirituelle. Paris: Alcan.

BROAD, C.D. 1925. The Mind and its Place in Nature. London: Kegan Paul.

BROWN, M.H. 1987. Wilderness vision quest: Exploring the frontiers in human resource development. Paper presented at the 4th World Wilderness Congress, Colorado.

CHARDIN, P. TEILHARD DE 1966. Man's Place in Nature: The Human Zoological Group. London: Collins.

DE FLEUR, M.L. and S.J. BALL-ROKEACH. 1982. Theories of Mass Communication. New York: Longman.

DEVALL, B. and G. SESSIONS. 1985. Deep Ecology. Salt Lake City: Peregrine Smith.

DRIESCH, H. 1922. Der Vitalismus als Geschichte und Lehre. Leipzig: J.A. Barth.

DU TOIT, A.P. 1988. What is life? In: VORSTER, W.S. (ed.). The Right to Life - Questions in Bioethics. Pretoria: Unisa.

ENVIRONMENTAL AFFAIRS, DEPARTMENT OF. 1989. White Paper on Environmental Education.

HEISENBERG, W. 1958. The Physicist's Conception of Nature. London: Hutchinson.

JOUBERT, S.C.J. 1986. Meesterplan vir die bestuur van die Nasionale Krugerwildtuin. Internal report: National Parks Board.

LOADER, J.A. 1987. Image and order: Old Testament perspectives on the ecological crisis. In: VORSTER, W.S. (ed.). Are we Killing God's Earth? Pretoria: Unisa.

MILBRATH, L.W. 1984. A proposed value structure for a sustainable society. The Environmentalist 4, Supplement 7: 113-124.

PLAYER, I. (ed.) 1979. Voices of the Wilderness. Cape Town: Ball.

POPPER, K.R. 1972. Objective Knowledge. Oxford: Clarendon.

ROTHENBERG, D. 1987. A platform of Deep Ecology. The Environmentalist 7(3): 185-190.

RUSSELL, E.S. 1945. The Directiveness of Organic Activities. Cambridge: Cambridge University Press.

SAGAN, D. and L. MARGULIS, 1984. Gaia and philosophy, In: ROUNER, L.S. (ed.). On Nature. Notre Dame: University of Notre Dame Press.

SKOLIMOWSKI, H. 1984. Eco-Ethics as the foundation of conservation.The Environmentalist 4, Supplement 7: 45-51.

STERLING, S.R. 1985. Culture, ethics, and the environment - towards the new synthesis. The Environmentalist 5(3): 197-206.

SUTTIE, J. 1984. Wilderness: A medium for improving psychological health. The Environmentalist 4(4): 295-299.

THOMSON, R. 1986. On Wildlife 'Conservation'. Cape Town: United Publishers.

WHITEHEAD, A.N. 1929 [1960]. Process and Reality - An Essay in Cosmology. London: Macmillan. 